\title{
Thermal Tolerance is linked with Virulence in a Fish Pathogen
}

2

3

4 Roghaieh Ashrafi1, ${ }^{1,}$, Matthieu Bruneaux ${ }^{1}$, Lotta-Riina Sundberg1, Katja Pulkkinen², 5 Janne Valkonen ${ }^{1}$, Tarmo Ketola ${ }^{1}$

61 University of Jyväskylä, Centre of Excellence in Biological Interactions. Department of

7 Biological and Environmental Science (and Nanoscience Center). P.O. Box 35. FI-40014

8 University of Jyväskylä. FINLAND

$9 \quad 2$ University of Jyväskylä, Department of Biological and Environmental Science. P.O. Box 35.

10 FI-40014 University of Jyväskylä. FINLAND

11 *Corresponding author e-mail: roghaieh.ashrafi@jyu.fi

12

16 Keywords: Virulence, thermal tolerance, environmentally growing opportunistic bacteria, 


\section{ABSTRACT}

28 Although increase in temperatures may boost the number of pathogens, a

29 complex process involving the interaction of a susceptible host, a virulent strain, and

30 environmental factors would influence disease virulence in unpredictable ways.

31 Here we explored if the virulence of an environmentally growing opportunistic fish

32 pathogen, Flavobacterium columnare, would be malleable to evolutionary changes via

33 correlated selection on thermal tolerance. Virulence among the strains increased over

34 years, but tolerance to higher temperatures was associated with reduced virulence.

35 Our results suggest that observed increase in frequency of columnaris epidemics

36 over the last decade is most likely associated with increased length of growing

37 season, or other time dependent change in environment, rather than increased

38 regional average temperatures. Our results also indicate that most virulent bacteria

39 had weaker ability to tolerate outside host environments, which suggest trade-off

40 between more obligate pathogen behaviour and ability to grow outside host. 


\section{INTRODUCTION}

Climate projections suggest that changing climate not only affects the average temperature but also the occurrence of extreme and variable temperatures ${ }^{1}$. Such changes in climate alter extinction risks, provoke range shifts and cause selection pressure to favour genotypes that are adapted to cope with these new environments 2-4. Microbes, many of which have the capacity to be or become pathogens, are expected to adapt rapidly. Global warming may benefit many bacterial species, since they will face milder winter months resulting in greater overwintering success, increased numbers of generations and, thus, higher pathogen densities to damage hosts 5, 6. Environmentally growing opportunistic pathogens, in contrast to obligate (fully host-dependent) pathogens, can utilize outside host resources, making them very sensitive to selection pressures outside the host ${ }^{7}$. Therefore, predicting the effect of climate warming on environmental opportunistic bacteria with life cycles both outside and inside the host present a particular challenge because pathogen fitness in both environments may be differentially affected by temperature 8 . Although the ability to stay alive in the environment, e.g. as inactive spores, has been linked with high virulence 9, 10, pathogens can also evolve towards a more benign virulence since investments in resource acquisition and defence in the outside-environments can trade off with traits connected to virulence ${ }^{11,12}$. Previous studies suggest that higher temperatures select genotypes that tolerate hotter temperatures, whereas fluctuations in temperature should select for more generalist genotypes with improved tolerance to extreme temperatures ${ }^{13-18}$. Nevertheless, it has remained unclear how climate warming might affect growth parameters in environmentally growing opportunistic pathogens, and how this correlates with their potential to cause disease.

Understanding the selection pressures underlying the evolution of virulence in outside-host environments is crucial in the current context of climate change, especially for diseases affecting world food production. Flavobacterium columnare, the etiological agent of columnaris disease in farmed fish, is an opportunistic fish pathogen which severely impacts freshwater aquaculture worldwide 19, 20 . Specifically, this bacterium can cause infections both in cold and warm water fish 
87 species ${ }^{21}$. The temperature range in which it can grow actively is approximately 15 to $35^{\circ} \mathrm{C}{ }^{19}$. Previous work on this bacterium in the context of global warming and even a number of virulent pathogens has focused mainly on long-term empirical data examining the relationship between mean ambient temperature and disease prevalence 22, 23. Analysis of more than 20 years' worth of data has showed a significant positive effect of mean water temperature on the prevalence of columnaris disease at two fish farms ${ }^{22}$. However, it is still unclear if climate change will impact the thermal performance of this bacterium at long term by selecting more thermo-tolerant strains and if such changes may have any effect on bacterial virulence. This is important information for regions where climate change is expected to be most severe, such as Finland where average annual temperature is predicted to rise nearly twice as fast as the average temperature for the whole globe 24 .

Thermal tolerance is usually depicted via thermal performance curves (TPC) composed from the measured performance of a genotype in different thermal environments. Assuming that thermal performance curves obtained from measurements done in constant environments can be used to predict how genotypes survive under fluctuations $25-27$, adaptation to fluctuating environments could occur either via overall elevated TPC or via broadened TPC 16, 17, 28. The key ecophysiological parameters that characterize thermal performance curves are the critical thermal thresholds which represent the lower $\left(\mathrm{CT}_{\min }\right)$ and upper $\left(\mathrm{CT}_{\max }\right)$ temperatures at which performance (e.g. growth or yield of bacteria) is zero, the optimum temperature $\left(\mathrm{T}_{\mathrm{opt}}\right)$ at which performance is maximal, and the maximum value of performance itself $\left(\mu_{\max }\right)$. In addition to these parameters, variation in TPC can also be characterized using principal component analysis in order to identify the main patterns of performance variation among the genotypes 29, 30. However, the latter method has been rarely applied to thermal performance data in bacteria.

In the present study, we measured bacterial growth at five different temperatures (spanning from 17 to 32 that matches typical summer growth season in Finland, and in the near future) in order to characterize the temperature dependence of maximum biomass (hereafter yield) in 49 F. columnare isolates collected across 
118 Finland. Based on this data, we examined (i) variation of thermal performance in isolates, and (ii) the link between thermal performance and bacterial virulence, using virulence data measured in a separate experiment. We showed that Finnish isolates differed in maximum yield and limits of thermal range, and that their good tolerance to high temperatures was linked to lowered virulence.

\section{MATERIAL AND METHODS \\ F. columnare strains and culture conditions}

We used 49 Finnish F. columnare isolates for which genotypes were previously determined by the conventional MLST method using six loci 31 (Supplementary Table 1). All strains, belonging to broadly defined genetic group characterized by good low-temperature tolerance (genomovar I) 31, 32, were originally isolated from eight fish farms, from both Southern (approx. $\left.65^{\circ} \mathrm{N}\right)$ and Northern $\left(62^{\circ} \mathrm{N}\right)$ parts of Finland (Supplementary Table 1), from fish or tank water using standard culture methods with modified Shieh medium 33, Shieh medium supplemented with tobramycin ${ }^{34}$, or AO-agar 35.

\section{Thermal performance measurements}

Bacterial isolates were grown overnight in modified Shieh medium under constant agitation $(120 \mathrm{rpm})$ in room temperature and further sub-cultured to fresh medium in ratio of 1:10 for another $16-18 \mathrm{~h}$ under the same conditions. Sterile $15 \mathrm{ml}$ tubes containing $5.5 \mathrm{ml}$ of bacterial culture were centrifuged for $5 \mathrm{~min}$ in $4^{\circ} \mathrm{C}$ at 3500 $g$, after which the supernatant was discarded. $240 \mu \mathrm{l}$ of concentrated bacterial culture was mixed with $60 \mu \mathrm{l}$ of $10 \%$ of glycerol and $10 \%$ of fetal calf serum mixture on 100well Bioscreen $C \circledR$ plate in a randomized order and stored at $-80^{\circ} \mathrm{C}$. Prior to growth measurements, bacterial isolates were inoculated to a new Bioscreen plate containing $400 \mu \mathrm{l}$ fresh modified Shieh medium in each well directly from the frozen Bioscreen plate using heat-sterilized cryo-replicator (Enzyscreen B.V., Haarlem, Netherlands 36). After $24 \mathrm{~h}$ incubation at $25^{\circ} \mathrm{C}$, inoculums of $40 \mu \mathrm{L}$ of individual bacterial strains from these pre-cultures were distributed into a Bioscreen plate containing $400 \mu \mathrm{L}$ of 
152 fresh modified Shieh medium in each well for the growth measurements. Growth

153 experiments were run simultaneously in duplicate in two 100-well plates in a

154 Bioscreen C spectrophotometer (Oy Growth Curves Ab Ltd, Finland) over two to 155 eight days depending on the experimental temperature, at five different 156 temperatures $\left(17^{\circ}, 20^{\circ}, 22^{\circ}, 29^{\circ}\right.$ and $\left.32^{\circ} \mathrm{C}\right)$. The bacteria were cultured without 157 shaking, and optical density (OD) measurements were performed at 5-minute 158 intervals (absorbance at $600 \mathrm{~nm}$ ). The growth curves were analysed as described in 159 Ketola et al. 16 to estimate maximum growth rate and maximum biomass or yield. 160 Maximum yield estimates were more robust than maximum growth estimates due to the sensitivity of the latter to noise in the early phase of the growth curves.

162 Consequently, we chose to use maximum yield as a measure for strain performance 163 at a given temperature.

Two alternative approaches were used to analyse the thermal performance data: (i) curve fitting followed by estimation of TPC parameters $\left(\mathrm{CT}_{\min }\right.$, $\left.\mathrm{CT}_{\max }, \mathrm{T}_{\mathrm{opt}}, \mu_{\max }\right)$ for each strain and (ii) principal component analysis (PCA) on the discrete performance measurements.

168

169

170

\section{Thermal performance curve fitting and parameter estimation}

We used the TableCurve 2D software (version 5.01; Systat Software, Inc. 2002) to select a set of 1960 candidate equations to describe the relationship between yield and temperature. Using data from a subset of experimental strains, all equations using two- and three-term functions, with intercept available in the TableCurve 2D library, were fitted and the resulting fits with large $R^{2}$ values were visually inspected. Candidate equations were selected based on the fulfilment of the following criteria to ensure a biologically meaningful fit: (i) "bell-shaped" curve with maximum yield occurring within the experimental thermal range, (ii) mostly concave curve (i.e. curves with several and clear local maximums in the experimental thermal range were discarded, but slight bumps were allowed), (iii) extrapolation outside the experimental thermal range predicted decreased performance (i.e the behaviour of the curve outside the experimental thermal range was consistent with biological expectations). In the end, the following 6 equations 
200

201

202

203

204

205

206

207

210

211

212

213

were chosen as candidates for a plausible model of the relationship between temperature $(\mathrm{x})$ and performance $(\mathrm{y})$ :

1) $y=a+b \cdot x^{2} \cdot \log (x)+c \cdot x^{3}$

(2) $y=a+b \cdot x+c \cdot x^{2}$

(3) $y=a+b \cdot x^{\frac{3}{2}}+c \cdot x^{2}$

(4) $y=\frac{1}{a+b \cdot \exp (x)+c \cdot \exp (-x)}$

(5) $y=a+b \cdot x+c \cdot \log (x)^{2}+d \cdot \sqrt{x}$

(6) $y=a+b \cdot \log (x)^{2}+c \cdot \log (x)+\frac{d \cdot \log (x)}{x}$,

where $a, b, c$ and $d$ are strain-specific curve parameters. The average $R^{2}$ values across the 49 strains used in this study were greater than 0.98 for each of those equations.

For each strain, a weighted-average thermal performance curve was built after fitting those six candidate equations, where AIC values were used to calculate a strain-specific weight for each of the six equations according to the formula:

$$
w_{i}=\frac{e^{-(\Delta A I C)_{i} / 2}}{\sum_{1 j 6} e^{-(\Delta A I C)_{j} / 2}},
$$

where $w_{i}$ is the weight assigned to the $i^{\text {th }}$ equation and $(\triangle A I C)_{i}$ is the difference between the AIC of the $\mathrm{i}^{\text {th }}$ equation and the lowest AIC among the six equations for this strain. While acknowledging that our procedure for the selection of candidate equations might introduce some subjectivity in the choice of candidate curves, keeping 6 different candidate equations and producing a weighted-average model based on their AIC values allowed for a variety of shapes in the final fitted curves with an overall good quality of fit, as shown in Supplementary Figure 1.

The obtained average thermal performance curves were used to determine maximum performance $\mu_{\max }$ and optimal temperature $\mathrm{T}_{\mathrm{opt}}$. We decided not to extrapolate unreasonably the thermal performance curves to determine $\mathrm{CT}_{\min }$ values, but instead chose to estimate thermal ranges by calculating for each strain the temperatures at which its TPC reached half its maximum performance, hereafter $\mathrm{CT}_{50 / \text { low }}$ and $\mathrm{CT}_{50 / \text { high. }}$ Growth at lower temperatures falls gradually and the growth in this species is already un-measurable at $15^{\circ} \mathrm{C}$, causing estimation inaccuracy if curve fitting and in estimating CT min. Thermal performance breadth (TPB) was 
216 defined as the difference between the estimated $\mathrm{CT}_{50 / \text { high }}$ and $\mathrm{CT}_{50 / \text { low }} \mathrm{A}$ visual

217 inspection of the fitted curves was performed to remove $\mathrm{CT}_{50 / \text { low }}$ (for 8 strains) and

$218 \mathrm{~T}_{\text {opt }}$ values (for 3 strains) which were unreliable given the shape of the fit for a

219 particular strain (e.g. very flat plateau at $\mu_{\max }$, unreliable extrapolation for $\mathrm{CT}_{50 / \text { low }}$ ),

220 resulting in 41 strains with all TPC parameters.

\section{PCA on yield measurements}

Since PCA is sensitive to outlier data points departing from normal distributions, we visually inspected normal quantile-quantile plots of the yield data to identify and remove three outliers out of 49 strains prior to PCA. PCA was performed using the covariance matrix of maximum yields in five temperatures. Since the outliers were removed only to avoid unduly affecting the PCA by their departure from normality but were otherwise biologically meaningful, the coordinates of all 49 strains along each principal component (PC) were then calculated based on the PCA loadings obtained from the subset of 46 strains. In order to facilitate the biological interpretation of the patterns of variation described by each PC, we predicted the TPC of hypothetical strains located at the extreme boundaries of the $95 \%$ range of the coordinates of experimental strains along each PC using the inverse of the PCA matrix.

Virulence assay

A virulence experiment was conducted according to the Finnish Act on the Use of Animals for Experimental Purposes, under permission ESAVI-201005569/Ym-23 granted for L-RS by the National Animal Experiment Board at the Regional State Administrative Agency for Southern Finland. Virulence of the 49 bacterial strains was assessed in an experiment using zebra fish (Danio rerio). The fish were infected using bacterial cultures grown overnight in fresh modified Shieh medium and adjusted at $4 \times 10^{5}$ colony-forming units (CFU) $\mathrm{mL}^{-1}$. Ten fish per bacterial strain were individually challenged in $500 \mathrm{ml}$ of water by adding $500 \mu \mathrm{l}$ of adjusted bacterial culture directly into the experimental aquaria. The water temperature was maintained at $25^{\circ} \mathrm{C}$ during all experiments, which is close to the 
249 mean $\mathrm{T}_{\text {opt }}$ of the strains used. It has been shown than the zebra fish can be used as a 250 reliable model in virulence experiments since it shares the temperature optimum of 251 this pathogen ${ }^{37}$. Aquaria containing fish were randomly placed on shelves in the 252 experimental room to reduce the differences between aquaria. This infection method 253 has been shown to produce a rapid onset of disease in fish, bringing out strain 254 differences 37,38 . As a control, 10 fish were individually exposed to $500 \mu$ l of sterile 255 Shieh medium. Disease signs and fish morbidity were monitored in two hour 256 intervals for 97 hours. Morbid fish that had lost their natural swimming buoyancy, and which did not respond to external stimuli, were considered dead and removed from the experiment, and euthanatized by cutting the spinal cord to avoid the suffering of the fish. The experiment was conducted according to the Finnish Act on the Use of Animals for Experimental Purposes, under permission granted by the National Animal Experiment Board at the Regional State Administrative Agency for Southern Finland for L-RS.

\section{Statistical analyses of thermal performance data} strain isolation (continuous variable) and geographical location (categorical variable, 2 levels: Northern and Southern Finland) on thermal performance were assessed using model selection starting from a full linear model specified as:

where Performance was either one of the thermal performance curve parameters estimated from curve fitting $\left(\mu_{\max }, \mathrm{T}_{\mathrm{opt}}, \mathrm{CT}_{50 / \text { low }}, \mathrm{CT}_{50 / \text { high }}\right.$ or $\left.\mathrm{TPB}\right)$ or coordinates along one of the principal components of interest (PC1, PC2 or PC3). No interaction between Group and Year or Group and Location was included in the starting model due to the imbalanced distribution of strains from different MSLT genotype groups across the years or across the geographical range of our study. Model selection was performed iteratively: at each step, variables were dropped one at a time and the significance of the change in fit for each dropped variable was tested using a Chi- 
281 square test (function drop1 in R). If the highest p-value for significance of change in 282 fit was greater than 0.10, the corresponding variable was dropped from the model 283 and the next selection step was performed; otherwise model selection was stopped. virulence data was analysed by considering fish survival as a binary variable (death/survival). The effects of explanatory variables on fish death were estimated using generalized linear mixed models (binomial family) with a logit link function and using strain identity as a random factor. Two full models differing in how they incorporated thermal performance as an explanatory variable (using either (i) PCs or (ii) TPC parameters) were used as starting models. The fixed effects used in those two initial models were:

(i) MLST genotype, year, location, PC1, PC2, and PC3 (49 strains)

(ii) MLST genotype, year, location, $\mu_{\max }, \mathrm{T}_{\mathrm{opt}}$, and $\mathrm{CT}_{50 / \text { high }}$ (46 strains)

$\mathrm{CT}_{50 / \text { low }}$ and TPB were not included in full model due to colinearity with CT high (Figure 1.). selection was performed starting from each of the full models and testing the effect of removing one variable out of MLST genotype, year and location at a time, and testing for the significance of the change in fit with a likelihood-ratio test (function drop1 in R). At each step, the variable with the highest $\mathrm{p}$-value for the significance of change in fit was dropped if this $\mathrm{p}$-value was greater than 0.10 . We did not remove any thermal performance variable included in the initial starting models since we wanted to consider all the thermal performance characteristics simultaneously in the models. We used the DHARMa package in $\mathrm{R} 39$ to assess the correctness of the residuals. 
TPC parameters were estimated from the AIC-weighted average curves for each of the 49 strains; due to uncertainty in estimated values for some fits, $\mathrm{T}_{\text {opt }}$ values were calculated for 46 strains, and $\mathrm{CT}_{50 / \text { low }}$ values for 41 strains (Supplementary Figure 1, Supplementary Table 1). A correlogram was built to explore pairwise correlations between TPC parameters (Figure 1): $\mathrm{CT}_{50 / \text { low }}$ and $\mathrm{CT}_{50 / \text { high }}$ were negatively correlated, suggesting a gradient between narrow and wide thermal performance range (specialist-generalist gradient). $\mathrm{T}_{\mathrm{opt}}$ was positively correlated with $\mathrm{CT}_{50 / \text { low }}$ but not with $\mathrm{CT}_{50 / \text { high }}$, which reflects a horizontal shift of the left-hand part of the TPC while maximum thermal tolerance would be more constrained. Finally, $\mu_{\max }$ was positively correlated with $\mathrm{CT}_{50 / \text { low }}$ and negatively correlated with $\mathrm{CT}_{50 / \text { high }}$ and TPB; this might reflect a trade-off between increased tolerance to a larger range of temperatures and higher maximum performance.

\section{Principal components describing variation in thermal performance}

We selected the first three principal components, which accounted for $93 \%$ of the variability of the yield measurements at 17, 22, 24, 29 and $32^{\circ} \mathrm{C}$ (Figure 2, Supplementary Table 2). Based on the predicted TPC along each PC (Figure 2), PC1 (describing $46 \%$ of the variation) is related to an increase in the thermal performance breadth by increasing yield at both extreme temperatures $\left(17^{\circ} \mathrm{C}\right.$ and $\left.32^{\circ} \mathrm{C}\right)$ while the maximum performance is unchanged along this component. PC1 is thus mostly a generalist-specialist axis. PC2 (describing 30\% of the variation) is characterized by a negative correlation between performance in cold and warm temperatures: PC2 can be seen as a cold adaptation/warm adaptation axis. PC3 (describing 17\% of the variation) corresponds to a change in the maximum performance, negatively correlated with performance in the coldest temperature but unrelated to performance at the warmest temperature.

\section{Determinants of thermal performance}

The MLST genotype affected all calculated thermal performance parameters ( $\mu_{\max }, \mathrm{T}_{\mathrm{opt}}, \mathrm{CT}_{50 / \text { low }}, \mathrm{CT}_{50 / \text { high }}$ and TPB) (Table 1). Year effect was close to significance 
348 for $\mu_{\max }$, with maximum performance decreasing slightly over the years (Table 1 ).

349 Geographical location had no significant effect on any TPC parameter.

350 Location had a significant effect on PC2 coordinates, with Northern strains

351 exhibiting lower PC2 values (Table 2), corresponding to cold adaptation (Figure 2).

352 MLST genotype had a significant effect on PC3 coordinates (negative correlation

353 between maximum performance and cold tolerance, Figure 2).

\section{DISCUSSION}

There is a growing body of evidence indicating that some pathogens become more prevalent 40,41 and more virulent at warmer temperatures ${ }^{42}$. For example, increased expression of virulence factors is correlated with increased temperature in Vibrio species 43,44 . Although global warming may increase the number of virulent pathogens, pathogens with free-living stages and ectothermic hosts are particularly susceptible to changes in temperature because temperature can have complex and opposing effects on different parts of the pathogen life cycles ${ }^{8}$. We explored if strains of an aquaculture-associated pathogen vary in their thermal performance, and if thermal performance was correlated with strain virulence. This type of information is crucial in predicting how future climate change scenarios could alter 
environmental pathogens' virulence via correlated selection on their thermal performance. In theory, due to co-evolutionary shifts in both host and the pathogen, virulence is expected to decrease over time, as fitness of both populations is optimized. However, virulence is context-dependent, as both biotic factors such as host condition ${ }^{46}$ and host density ${ }^{47}$ and abiotic factors such as temperature ${ }^{48}$ can influence virulence. For example, high environmental temperature could select for increased bacterial pathogenicity, in Serratia marcescens ${ }^{49}$.

We characterized the temperature dependency of maximum biomass production (i.e. yield) of 49 isolates of F. columnare that were collected from eight different areas located across Finland between 2003 and 2012. We performed temperature performance curves (TPC) and used principal component analysis on raw performance measurements to assess the variation of thermal performance between strains. Our results revealed that despite northern location Finnish F. columnare typically have a rather high optimum temperature between $23.7{ }^{\circ} \mathrm{C}$ and $27.9^{\circ} \mathrm{C}$ and an upper critical temperature for yield between $30.1^{\circ} \mathrm{C}$ and $34.7{ }^{\circ} \mathrm{C}$. Finnish lakes form predominantly closed and shallow basins (average depth about 7 metres) and surface waters may reach high temperatures in summer. Tolerance to high temperature might be necessary for inhabiting natural waters during summer since this bacterium has an environmental origin ${ }^{50}$. Consistent with the idea that cold tolerance is a key element for survival and growth in high latitudes, isolates from Northern Finland were more tolerant to colder temperatures than isolates from Southern Finland (see: PC2 in Figure 2 and effect of location on PC2 in Table 2). Our findings are in agreement with previous studies showing that selection may favour higher performance in higher altitude/latitude environments to guarantee successful reproduction and transmission during short growth seasons ${ }^{45}$.

On the other hand, ample amount of genotype dependent variation in all TPC parameters (Table 1, Figure 1) suggests thermal performance is strongly constrained by genetic background of the bacteria. These findings clearly indicate that thermal conditions can in principle have a strong effect on the genetic diversity of $F$. columnare in the environment, and therefore presumably also on disease dynamics. 
412 One would expect that F. columnare with high optimum temperatures may 413 lead to more epidemics in the future owing to climate change. Interestingly, 414 virulence was negatively correlated with upper thermal tolerance $\left(\mathrm{CT}_{50 / \mathrm{high}}\right)$ and 415 with thermal generalism (Tables 3 and 4). This suggests that not higher temperatures 416 or increased fluctuations associated with climate change should not select for higher 417 virulence in this species. However, since the $\mathrm{CT}_{50 / \text { high }}$ values are already very high 418 (beyond $30^{\circ} \mathrm{C}$ ) it is unlikely that any increase in temperatures in the near future 419 would select for changes in $\mathrm{CT}_{50 / \text { high }}$ in the strains isolated in Finland, due to clearly 420 lower maximum temperatures in fish farms. Furthermore, as the epidemics become 421 more frequent at the high temperatures, recurring antibiotic treatments during onset 422 of epidemics leave little possibility for co-selection for virulence and performance in 423 high temperatures to take place, especially when temperatures in the farming 424 environment rarely exceed $+25^{\circ} \mathrm{C}$ (supplementary Figure 3).

425 Guijarro et al. ${ }^{48}$ showed that numbers of bacterial diseases in aquaculture, 426 particularly those of freshwater, can occur at temperatures below bacterial optimal 427 growth (optimum growth temperature for the fastest growth under laboratory 428 conditions). Therefore, the constraints of maximum environmental temperature on 429 virulence should be relatively limited. This view is supported by considering 430 outbreaks of epidemics, which start to occur at farms when water temperatures 431 exceed ca. $18^{\circ} \mathrm{C}$, after which epidemics are often treated with antibiotics. 432 Temperature records from a fish farm in Central Finland over the past few decades 433 show that maximum temperatures during the outbreak season have not significantly 434 increased, but rather the overall growth season length has increased (Figure S3). Still, 435 our results show that Finnish F. columnare strains have become intrinsically more 436 virulent in recent years, as evidenced in our experiments under controlled laboratory 437 conditions where confounding effects such as increased environmental temperature, 438 variable nutrient availability or variable host density were removed (year effect in 439 Table 3 and Table 4 and figure 3-B) (see also ${ }^{51}$ ). Thus, yearly increases in virulence 440 could be a consequence of increased growing season, due to intensified fish farming 44151 , or due to some other time associated change in environment. 
We showed that maximum performance was overall negatively correlated with thermal performance breadth, suggesting a trade-off between generalism and 444 high-performance specialism (Figure 1). However, we did not find that generalist 445 genotypes with broader performance breadth would have lower biomass at 446 optimum temperatures and hence opposing the classic generalist-specialist trade off 447 hypothesis. It is noteworthy that theories are highly idealized and a "Jack of all 448 temperatures" does not always have to be a master of none ${ }^{52}$ : genotypes can have 449 broader thermal performance range without paying a visible performance cost at optimum conditions, but possibly involving a trade-off with other traits $14,16,54$, such as virulence 16,53 .

For environmentally growing opportunist pathogens, adaptations for more efficient exploitation of one growth environment could be expected to cause repercussions in pathogens ability for growth in the other environment 7 , such as host. Alternatively, the presence of virulence factors in the bacteria is unnecessary during the planktonic state but essential for the infection process, helping bacteria to save energy by not expressing virulence genes until they sense they have entered the host environment ${ }^{48}$. This could explain why more generalist strains with broader thermal performance breadth, were less virulent than more specialist ones (see: PC1 effect in Table 4 and Figure 3-A). Similarly, expression of virulence factors was found to lower the outside growth rate in Salmonella typhimurium 53 and adaptation to tolerate thermal fluctuations and predators have caused lowered virulence in experimental evolution settings ${ }^{11,16,49,55}$.

In conclusion, it seems that current problems with steadily increased severity of outbreaks and evolved virulence cannot be directly linked to increased mean temperature in fish farms and associated bacterial evolution. Still, the found clear genotype and location effects on several thermal tolerance parameters suggest that temperatures can play strong role in dictating which genotypes and clones of this important fish pathogen are successful in different thermal environments. 
472 We would like to thank Dr. Ilkka Kronholm and Dr. Elina Laanto for providing

473 constructive comments and help in improving the contents of this paper. We would

474 like to thank Dr. Päivi Rintamäki, Dr. Heidi Kunttu, MSc. Reetta Penttinen and Dr.

475 Elina Laanto for donating bacterial isolates for this study. We would also like to

476 thank MSc Jenni Marjakangas for valuable help in the lab. The authors want to thank

477 Yrjö Lankinen from Savon Taimen for providing the temperature data from

478 Tyyrinvirta. This work was supported by KONE foundation (Roghaieh Ashrafi via

479 project "Constraints of evolutionary adaptation to climate change" to Tarmo Ketola),

480 OLVI foundation (Roghaieh Ashrafi \#201620393), the Jane and Aatos Erkko

481 Foundation (Lotta-Riina Sundberg), Finnish Cultural Foundation (Katja Pulkkinen)

482 and Academy of Finland (Lotta-Riina Sundberg \#266879, Tarmo Ketola \# 278751,

483 Jouni Taskinen \# 260704 to Katja Pulkkinen) and Centre of Excellence in Biological

484 Interactions (\#252411, Prof. Johanna Mappes) to Roghaieh Ashrafi, Lotta-Riina

485 Sundberg, and Tarmo Ketola.

COMPETING INTERESTS

487 The authors declare no competing interests; financial or otherwise.

\section{REFERENCES}

1. Solomon, S. et al. IPCC, 2007: summary for policymakers. Climate change, 93-129 (2007).

2. Parmesan, C. Ecological and evolutionary responses to recent climate change. Annual Review of Ecology, Evolution, and Systematics, 637-669 (2006). 
3. Visser, M. E. Keeping up with a warming world; assessing the rate of adaptation to climate change. Proc. Biol. Sci. 275, 649-659 (2008).

4. Heino, J., Virkkala, R. \& Toivonen, H. Climate change and freshwater biodiversity: detected patterns, future trends and adaptations in northern regions. Biological Reviews 84, 39-54 (2009).

5. Burdon, J. \& Chilvers, G. Host density as a factor in plant disease ecology. Annu. Rev. Phytopathol. 20, 143-166 (1982).

6. Coakley, S. M., Scherm, H. \& Chakraborty, S. Climate change and plant disease management. Annu. Rev. Phytopathol. 37, 399-426 (1999).

7. Brown, S. P., Cornforth, D. M. \& Mideo, N. Evolution of virulence in opportunistic pathogens: generalism, plasticity, and control. Trends Microbiol. 20, 336-342 (2012).

8. Harvell, C. D. et al. Climate warming and disease risks for terrestrial and marine biota. Science 296, 2158-2162 (2002).

9. Day, T. Virulence evolution via host exploitation and toxin production in spore-producing pathogens. Ecol. Lett. 5, 471-476 (2002).

10. Walther, B. A. \& Ewald, P. W. Pathogen survival in the external environment and the evolution of virulence. Biological Reviews 79, 849-869 (2004).

11. Mikonranta, L., Friman, V. \& Laakso, J. Life history trade-offs and relaxed selection can decrease bacterial virulence in environmental reservoirs. PloS one 7, e43801 (2012).

12. Sundberg, L. R., Kunttu, H. M. \& Valtonen, E. T. Starvation can diversify the population structure and virulence strategies of an environmentally transmitting fish pathogen. BMC microbiology 14, 1 (2014).

13. Condon, C. et al. Indirect selection of thermal tolerance during experimental evolution of Drosophila melanogaster. Ecology and evolution 5, 1873-1880 (2015).

14. Condon, C., Cooper, B. S., Yeaman, S. \& Angilletta, M. J. Temporal variation favors the evolution of generalists in experimental populations of Drosophila melanogaster. Evolution 68, 720-728 (2014).

15. Duncan, A. B., Fellous, S., Quillery, E. \& Kaltz, O. Adaptation of Paramecium caudatum to variable conditions of temperature stress. Res. Microbiol. 162, 939-944 (2011).

16. Ketola, T. et al. Fluctuating temperature leads to evolution of thermal generalism and preadaptation to novel environments. Evolution 67, 2936-2944 (2013). 
554

555

556

557

558

559

560

561

562

563

564

565

566

567

568

569

570

571

572

573

574

575

576

577

578

579

580

581

582

583

584

585

586

587

588

589

590

591

592

593

594

595

596

597

598

599
17. Levins, R. in Evolution in changing environments: some theoretical explorations (Princeton University Press, 1968).

18. Kassen, R. The experimental evolution of specialists, generalists, and the maintenance of diversity. J. Evol. Biol. 15, 173-190 (2002).

19. Declercq, A. M., Haesebrouck, F., Van den Broeck, W., Bossier, P. \& Decostere, A. Columnaris disease in fish: a review with emphasis on bacterium-host interactions. Vet. Res. 44, 27-44 (2013).

20. Bernardet, J. \& Grimont, P. A. Deoxyribonucleic acid relatedness and phenotypic characterization of Flexibacter columnaris sp. nov., nom. rev., Flexibacter psychrophilus sp. nov., nom. rev., and Flexibacter maritimus Wakabayashi, Hikida, and Masumura 1986. Int. J. Syst. Bacteriol. 39, 346-354 (1989).

21. Schneck, J. \& Caslake, L. Genetic diversity of Flavobacterium columnare isolated from fish collected from warm and cold water. J. Fish Dis. 29, 245-248 (2006).

22. Karvonen, A., Rintamäki, P., Jokela, J. \& Valtonen, E. T. Increasing water temperature and disease risks in aquatic systems: climate change increases the risk of some, but not all, diseases. Int. J. Parasitol. 40, 1483-1488 (2010).

23. Pulkkinen, K. et al. Intensive fish farming and the evolution of pathogen virulence: the case of columnaris disease in Finland. Proc. Biol. Sci. 277, 593-600 (2010).

24. Ruosteenoja, K., Jylhä, K. \& Kämäräinen, M. Climate Projections for Finland under the RCP Forcing Scenarios. Geophysica 51, 17-50 (2016).

25. Sinclair, B. J. et al. Can we predict ectotherm responses to climate change using thermal performance curves and body temperatures? Ecol. Lett. 19, 1372-1385 (2016).

26. Huey, R. B., Berrigan, D., Gilchrist, G. W. \& Herron, J. C. Testing the adaptive significance of acclimation: a strong inference approach. Am. Zool. 39, 323-336 (1999).

27. Ketola, T. \& Saarinen, K. Experimental evolution in fluctuating environments: tolerance measurements at constant temperatures incorrectly predict the ability to tolerate fluctuating temperatures. J. Evol. Biol. 28, 800-806 (2015).

28. Scheiner, S. M. \& Yampolsky, L. Y. The evolution of Daphnia pulex in a temporally varying environment. Genet. Res. 72, 25-37 (1998).

29. Huey, R. B. \& Kingsolver, J. G. Evolution of thermal sensitivity of ectotherm performance. Trends in Ecology E Evolution 4, 131-135 (1989). 
600 30. Izem, R. \& Kingsolver, J. G. Variation in continuous reaction norms: quantifying

601 directions of biological interest. Am. Nat. 166, 277-289 (2005).

602 sequence analysis scheme for characterization of Flavobacterium columnare isolates. BMC microbiology 15, 243 (2015).

32. Suomalainen, L., Kunttu, H., Valtonen, E., Hirvela-Koski, V. \& Tiirola, M. Molecular diversity and growth features of Flavobacterium columnare strains isolated in Finland. Dis. Aquat. Org. 70, 55-61 (2006).

33. Song, Y., Fryer, J. \& Rohovec, J. Comparison of six media for the cultivation of Flexibacter columnaris. Fish Pathol. 23, 91-94 (1988).

34. Decostere, A., Haesebrouck, F. \& Devriese, L. A. Shieh medium supplemented with tobramycin for selective isolation of Flavobacterium columnare (Flexibacter columnaris) from diseased fish. J. Clin. Microbiol. 35, 322-324 (1997).

35. Anaker, R. L. \& Ordal, E. J. Studies on the myxobacterium Chondrococcus columnaris. I. Serological typing. J. Bacteriol. 78, 25-32 (1959).

36. Duetz, W. A. et al. Methods for intense aeration, growth, storage, and replication of bacterial strains in microtiter plates. Appl. Environ. Microbiol. 66, 2641-2646 (2000).

37. Kinnula, H., Mappes, J., Valkonen, J. K. \& Sundberg, L. The Influence of Infective Dose on the Virulence of a Generalist Pathogen in Rainbow Trout (Oncorhynchus mykiss) and Zebra Fish (Danio rerio). PloS one 10, e0139378 (2015).

38. Laanto, E., Penttinen, R. K., Bamford, J. K. \& Sundberg, L. Comparing the different morphotypes of a fish pathogen-implications for key virulence factors in Flavobacterium columnare. BMC microbiology 14, 170 (2014).

39. Hartig. DHARMa: Residual Diagnostics for Hierarchical (Multi-Level/Mixed) Regression Models. $\mathrm{R}$ package version 0.1.2. https://CRAN.Rproject.org/package=DHARMa, (last Accessed November 2016). (2016).

40. Chiaramonte, L., Munson, D. \& Trushenski, J. Climate Change and Considerations for Fish Health and Fish Health Professionals. Fisheries 41, 396-399 (2016).

41. Sterud, E. et al. Severe mortality in wild Atlantic salmon Salmo salar due to proliferative kidney disease (PKD) caused by Tetracapsuloides bryosalmonae (Myxozoa). Dis. Aquat. Org. 77, 191-198 (2007).

42. Smith, K. F. et al. Global rise in human infectious disease outbreaks. J. R. Soc. Interface 11, 20140950 (2014). 
646

647

648

649

650

651

652

653

654

655

656

657

658

659

660

661

662

663

664

665

666

667

668

669

670

671

672

673

674

675

676

677

678

679

680

681

682

683

684

685

686

687

688

689

690

691
43. Mahoney, J. C., Gerding, M. J., Jones, S. H. \& Whistler, C. A. Comparison of the pathogenic potentials of environmental and clinical vibrio parahaemolyticus strains indicates a role for temperature regulation in virulence. Appl. Environ. Microbiol. 76, 7459-7465 (2010).

44. Oh, M. H., Lee, S. M., Lee, D. H. \& Choi, S. H. Regulation of the Vibrio vulnificus hupA gene by temperature alteration and cyclic AMP receptor protein and evaluation of its role in virulence. Infect. Immun. 77, 1208-1215 (2009).

45. Yang, L. et al. Trade-offs and evolution of thermal adaptation in the Irish potato famine pathogen Phytophthora infestans. Mol. Ecol. (2016).

46. Pulkkinen, K. \& Ebert, D. Host starvation decreases parasite load and mean host size in experimental populations. Ecology 85, 823-833 (2004).

47. Bieger, A. \& Ebert, D. Expression of parasite virulence at different host population densities under natural conditions. Oecologia 160, 247-255 (2009).

48. Guijarro, J. A., Cascales, D., García-Torrico, A. I., García-Domínguez, M. \& Méndez, J. Temperature-dependent expression of virulence genes in fish-pathogenic bacteria. Frontiers in microbiology 6 (2015).

49. Friman, V. et al. High temperature and bacteriophages can indirectly select for bacterial pathogenicity in environmental reservoirs. PloS one 6, e17651 (2011).

50. Kunttu, H. M., Sundberg, L. R., Pulkkinen, K., \& Valtonen, E. T. Environment may be the source of Flavobacterium columnare outbreaks at fish farms. Environmental microbiology reports, 4(4), 398-402 (2012).

51. Sundberg, L. R. et al. Intensive aquaculture selects for increased virulence and interference competition in bacteria. Proc. Biol. Sci. 283, 20153069 (2016).

52. Angilletta, M. J. in Thermal adaptation: a theoretical and empirical synthesis (Oxford University Press, 2009).

53. Sturm, A. et al. The cost of virulence: retarded growth of Salmonella Typhimurium cells expressing type III secretion system 1. PLoS Pathog 7, e1002143 (2011).

54. Huey, R. B. \& Hertz, P. E. Is a jack-of-all-temperatures a master of none? Evolution 38, 441-444 (1984).

55. Zhang, J. et al. Association of colony morphotypes with virulence, growth and resistance against protozoan predation in the fish pathogen Flavobacterium columnare. FEMS Microbiology Ecology. 89: 553-562 (2014). 
bioRxiv preprint doi: https://doi.org/10.1101/188185; this version posted September 13,2017 . The copyright holder for this preprint (which was not certified by peer review) is the author/funder, who has granted bioRxiv a license to display the preprint in perpetuity. It is made available under aCC-BY-NC-ND 4.0 International license.

692

693

694

695

696

697

698

699

700

701

702

703

704

705

706

707

708

709

710

711

712

713

714

715

716

717

718

719

720

721

722

723

724

725

726

727

728

729

730

731

732

733

734

735

736

737

738 
68

9

\section{FIGURES AND TABLES:}

Figure 1. Correlogram for thermal performance parameter estimates. Upper triangle, Pearson's product moment correlation coefficients between pairs of variables. The numbers in brackets indicate the $95 \%$ confidence interval. Lower triangle, scatter plot between pairs of variables. When the Pearson's product moment correlation coefficient is significant ( $\mathrm{p}$-value < 0.05), a dashed line indicates the ranked major axis. For the upper triangle, the color coding on a green to red scale matches the correlation coefficient value $(-1$, green; 0 , grey; +1 ; red). For the lower triangle, colors match MLST genotype: red, purple, green, and blue are for genotypes $\mathrm{C}, \mathrm{E}, \mathrm{G}$ and $\mathrm{A} \& \mathrm{H}$, respectively.

Figure 2. PCA results and their interpretation in terms of TPC patterns. Upper panels, prediction of TPC variation patterns along each of the first three PCs. Grey dashed line, average performance curve of the 49 strains used in this study. Orange and green lines, performance curves of hypothetical strains with coordinates at the lower and upper 95\% quantiles, respectively, along each PC, as depicted in the explicative panel on the right. Lower panels, loadings for each original temperature on the first three PCs.

Figure 3. Effect of PC1 coordinate and year of collection on strain virulence. Each marker represents the average mortality observed for a given strain. Fitted curves are plotted using the GLMM results presented in Table 4. Colours represent genotype groups. The black fitted line correspond weight-averaged fixed effect estimates based on the abundance of genotype groups in our dataset. Panel A, effect of PC1 coordinate on strain virulence. The three sub-panels illustrate how TPC varies from specialist to generalist phenotype along PC1. Panel B, effect of year of collection on strain virulence. 


\section{Table 1. Effect of MLST genotype, year of collection and location on strain}

772 thermal performance estimates. Marginal means are reported for each level of the

773 qualitative variables (Genotype, Location) and slope is reported for the continuous

774 variable Year. For variables which were removed from the final model, the reported

775 values (in italics) are the ones obtained in the last step before they were removed

776 during model selection.

\begin{tabular}{|c|c|c|c|c|c|}
\hline & Estimate & Std error & F-value & $(\mathrm{df1}, \mathrm{df2})$ & P-value \\
\hline \multicolumn{6}{|l|}{$\mu \max$} \\
\hline $\begin{array}{c}\text { Genotype } \\
\text { C }\end{array}$ & 1.091 & 0.012 & 18.7779 & $(3,44)$ & $<0.001$ \\
\hline E & 0.993 & 0.015 & & & \\
\hline G & 1.044 & 0.028 & & & \\
\hline$A \& H$ & 0.922 & 0.025 & & & \\
\hline Location & & & 1.8084 & $(1,43)$ & 0.186 \\
\hline Northern & 1.035 & 0.020 & & & \\
\hline Southern & 1.004 & 0.012 & & & \\
\hline \multirow{2}{*}{ Year } & & & 3.6614 & $(1,44)$ & 0.062 \\
\hline & -0.007 & 0.004 & & & \\
\hline \multicolumn{6}{|l|}{ Topt } \\
\hline Genotype & & & 3.2075 & $(3,42)$ & 0.033 \\
\hline C & 26.118 & 0.164 & & & \\
\hline $\mathrm{E}$ & 25.762 & 0.184 & & & \\
\hline $\mathrm{G}$ & 24.922 & 0.367 & & & \\
\hline A\&H & 25.660 & 0.300 & & & \\
\hline Location & & & 0.6578 & $(1,41)$ & 0.422 \\
\hline Northern & 25.427 & 0.269 & & & \\
\hline Southern & 25.681 & 0.157 & & & \\
\hline \multirow[t]{2}{*}{ Year } & & & 0.3254 & $(1,40)$ & 0.572 \\
\hline & -0.028 & 0.050 & & & \\
\hline \multicolumn{6}{|l|}{ CTlow } \\
\hline Genotype & & & 5.2715 & $(3,37)$ & 0.004 \\
\hline C & 17.577 & 0.178 & & & \\
\hline $\mathrm{E}$ & 16.511 & 0.212 & & & \\
\hline G & 17.028 & 0.397 & & & \\
\hline $\mathrm{A} \& \mathrm{H}$ & 16.668 & 0.459 & & & \\
\hline Location & & & 0.2220 & $(1,35)$ & 0.640 \\
\hline Northern & 16.864 & 0.320 & & & \\
\hline Southern & 17.036 & 0.199 & & & \\
\hline Year & & & 1.0523 & $(1,36)$ & 0.312 \\
\hline & 0.057 & 0.055 & & & \\
\hline \multicolumn{6}{|l|}{ CThigh } \\
\hline Genotype & & & 7.3380 & $(3,45)$ & $<0.001$ \\
\hline C & 31.570 & 0.167 & & & \\
\hline E & 32.471 & 0.200 & & & \\
\hline G & 31.107 & 0.400 & & & \\
\hline $\mathrm{A} \& \mathrm{H}$ & 32.722 & 0.326 & & & \\
\hline Location & & & 0.5217 & $(1,44)$ & 0.474 \\
\hline Northern & 32.144 & 0.285 & & & \\
\hline Southern & 31.903 & 0.171 & & & \\
\hline \multirow{2}{*}{ Year } & & & 0.0093 & $(1,43)$ & 0.924 \\
\hline & 0.005 & 0.054 & & & \\
\hline \multicolumn{6}{|l|}{ TPB } \\
\hline Genotype & & & 7.8427 & $(3,37)$ & $<0.001$ \\
\hline C & 13.994 & 0.275 & & & \\
\hline $\mathrm{E}$ & 15.970 & 0.328 & & & \\
\hline G & 14.079 & 0.614 & & & \\
\hline $\mathrm{A} \& \mathrm{H}$ & 15.437 & 0.709 & & & \\
\hline Location & & & 0.4048 & $(1,35)$ & 0.529 \\
\hline Northern & 15.080 & 0.496 & & & \\
\hline Southern & 14.721 & 0.308 & & & \\
\hline Year & & & 0.6543 & $(1,36)$ & 0.424 \\
\hline & -0.069 & 0.086 & & & \\
\hline
\end{tabular}


778 Table 2. Effect of MLST genotype, year of collection and location on strain

779 coordinates along PCs. Marginal means are reported for each level of the qualitative

780 variables (Genotype, Location) and slope is reported for the continuous variable

781 Year. For variables, which were removed from the final model, the reported values

782 (in italics) are the ones obtained in the last step before they were removed during

783 model selection.

784

785

786

787

788

789

790

791

792

793

794

795

796

797

798

799

800

801

802

803

804

805

\begin{tabular}{|c|c|c|c|c|c|}
\hline & Estimate & Std error & F-value & (df1, df2) & P-value \\
\hline \multicolumn{6}{|l|}{ PC1 } \\
\hline Genotype & & & 1.3983 & $(3,45)$ & 0.256 \\
\hline C & -0.006 & 0.040 & & & \\
\hline$E$ & 0.063 & 0.048 & & & \\
\hline$G$ & -0.123 & 0.097 & & & \\
\hline$A \& H$ & 0.091 & 0.079 & & & \\
\hline Location & & & 2.1451 & $(1,44)$ & 0.150 \\
\hline Northern & 0.092 & 0.068 & & & \\
\hline Southern & -0.025 & 0.041 & & & \\
\hline \multirow[t]{2}{*}{ Year } & & & 0.1342 & $(1,43)$ & 0.716 \\
\hline & -0.005 & 0.013 & & & \\
\hline \multicolumn{6}{|l|}{ PC2 } \\
\hline Genotype & & & 0.8297 & $(3,43)$ & 0.485 \\
\hline C & -0.030 & 0.040 & & & \\
\hline$E$ & -0.037 & 0.059 & & & \\
\hline$G$ & -0.146 & 0.093 & & & \\
\hline$A \& H$ & 0.038 & 0.079 & & & \\
\hline Location & & & 6.1481 & $(1,47)$ & 0.017 \\
\hline Northern & -0.094 & 0.039 & & & \\
\hline Southern & 0.030 & 0.031 & & & \\
\hline \multirow[t]{2}{*}{ Year } & & & 0.8896 & $(1,46)$ & 0.351 \\
\hline & 0.009 & 0.010 & & & \\
\hline \multicolumn{6}{|l|}{ PC3 } \\
\hline Genotype & & & 9.8268 & $(3,45)$ & $<0.001$ \\
\hline C & -0.060 & 0.018 & & & \\
\hline E & 0.051 & 0.021 & & & \\
\hline $\mathrm{G}$ & 0.002 & 0.042 & & & \\
\hline$A \& H$ & 0.120 & 0.034 & & & \\
\hline Location & & & 1.6877 & $(1,44)$ & 0.201 \\
\hline Northern & -0.005 & 0.030 & & & \\
\hline Southern & 0.040 & 0.018 & & & \\
\hline \multirow[t]{2}{*}{ Year } & & & 1.2299 & $(1,43)$ & 0.274 \\
\hline & 0.006 & 0.006 & & & \\
\hline
\end{tabular}

806

807

808 
810 Table 3. Effect of strain characteristics on virulence (using PCs coordinates).

811 Model used in R: death genotype + year + location + PC1 + PC2 + PC3 + (1| strain),

812 with a binomial family distribution and a logit link function. Marginal means and

813 standard errors are reported for each different level of qualitative variables

814 (Genotype and Location) in the original response scale (pDeath) while slope

815 estimates and standard errors in the logit scale are reported for the continuous

816 variables. For variables which were removed from the final model, the reported

817 values (in italics) are the ones obtained in the last step before they were removed

818 during model selection.

819

820

821

822

823

824

825

826

\begin{tabular}{|c|c|c|c|c|c|}
\hline & Estimate & $\begin{array}{l}\text { Std } \\
\text { error }\end{array}$ & Chi-square & Df & P-value \\
\hline Genotype & & & 4.4056 & 3 & 0.221 \\
\hline C & Pdeath $=0.665$ & 0.327 & & & \\
\hline E & Pdeath $=0.907$ & 0.135 & & & \\
\hline G & Pdeath $=0.203$ & 0.424 & & & \\
\hline$A \& H$ & Pdeath $=1.000$ & 0.001 & & & \\
\hline Location & & & 0.0303 & 1 & 0.862 \\
\hline Northern & Pdeath $=0.945$ & 0.098 & & & \\
\hline Southern & Pdeath $=0.923$ & 0.083 & & & \\
\hline \multirow[t]{2}{*}{ Year } & & & 4.3022 & 1 & 0.038 \\
\hline & 2.366 & 1.141 & & & \\
\hline \multirow[t]{2}{*}{$\mu \max$} & & & 0.4359 & 1 & 0.509 \\
\hline & 0.765 & 1.159 & & & \\
\hline \multirow[t]{2}{*}{ Topt } & & & 3.6112 & 1 & 0.057 \\
\hline & 1.765 & 0.929 & & & \\
\hline \multirow[t]{2}{*}{ CThigh } & & & 4.4010 & 1 & 0.036 \\
\hline & -2.588 & 1.234 & & & \\
\hline
\end{tabular}

827 
834 Table 4. Effect of strain characteristics on virulence (using TPC estimates). Model

835 used in R: death $\sim$ genotype + year + location $+\mu$ max + Topt + Topt $2+$ CT50/low +

836 CT50/high + (1 | strain), with a binomial family distribution and a logit link function.

837 Continuous variables (Year, umax, Topt, Topt2, CT50/low, CT50/high) were z-

838 normalised. Marginal means and standard errors are reported for each different

839 level of qualitative variables (Genotype and Location) in the original response scale

840 (pDeath) while slope estimates and standard errors in the logit scale are reported for

841 the continuous variables. For variables which were removed from the final model,

842 the reported values (in italics) are the ones obtained in the last step before they were

843 removed during model selection.

\begin{tabular}{|c|c|c|c|c|c|}
\hline & Estimate & Std error & Chi-square & Df & P-value \\
\hline Genotype & & & 7.1680 & 3 & 0.067 \\
\hline C & Pdeath $=0.844$ & 0.155 & & & \\
\hline E & Pdeath $=0.918$ & 0.122 & & & \\
\hline$G$ & Pdeath $=0.068$ & 0.148 & & & \\
\hline $\mathrm{A} \& \mathrm{H}$ & Pdeath $=1.000$ & 0.001 & & & \\
\hline Location & & & 0.2278 & 1 & 0.633 \\
\hline Northern & Pdeath $=0.835$ & 0.234 & & & \\
\hline Southern & Pdeath $=0.932$ & 0.075 & & & \\
\hline \multirow[t]{2}{*}{ Year } & & & 5.0896 & 1 & 0.024 \\
\hline & 1.944 & 0.862 & & & \\
\hline \multirow[t]{2}{*}{ PC1 } & & & 5.0548 & 1 & 0.025 \\
\hline & 1.935 & 0.861 & & & \\
\hline \multirow[t]{2}{*}{ PC2 } & & & 2.5536 & 1 & 0.110 \\
\hline & -1.351 & 0.846 & & & \\
\hline \multirow[t]{2}{*}{ PC3 } & & & 2.4667 & 1 & 0.116 \\
\hline & -1.492 & 0.950 & & & \\
\hline
\end{tabular}


867 Sup. Figure S1. TPC fits. Each plot represents maximum yield (y-axis) versus 868 temperature (x-axis). The strain name is indicated in each panel. For each strain, the 869 six candidate equations from TableCurve 2D were fitted (grey lines) and the 870 resulting curves were averaged using AIC-weights (red lines). Thermal performance 871 parameters (maximum yield, optimum temperature, $\mathrm{CT}_{50 / \text { low }}$ and $\mathrm{CT}_{50 / \text { high }}$ ) were 872 determined from the average curve for each strain. Asterisks denote strains for 873 which estimated values for either $\mathrm{CT}_{50 / \text { low }}$ alone $\left(^{*}\right)$ or $\mathrm{CT}_{50 / \text { low }}$ and $\mathrm{T}_{\text {opt }}(* *)$ were 874 deemed too unreliable and were set as missing values in downstream analyses.

Sup. Figure S2. Evolution of seasonal variation in water temperature in a Finnish average temperatures, (B) averages of three highest temperatures per month and (C) averages of three lowest temperatures per month. Red lines are fitted using a linear model within each month. The p-value for the significance of the year effect on the monthly values is reported for each month.

Sup. Table S1. Strain information. Site, year of isolation, source of isolation (fish or water), location of isolation, host species, sequence type (ST), genotype, maximum biomass (yield) estimates $\left(\mu_{\max }\right)$, optimal temperature $\left(\mathrm{T}_{\mathrm{opt}}\right)$, lower critical temperature $\left(\mathrm{CT}_{\min }\right.$ : this study $\left.\mathrm{CT}_{50 / \text { low }}\right)$, upper critical temperature $\left(\mathrm{CT}_{\text {max }}\right.$ : this study $\mathrm{CT}_{50 / \text { high }}$ ), thermal performance breadth (TPB) and mortality percentage estimates for the $49 \mathrm{~F}$. columnare strains from Finland.

Sup. Table S2. PCA summary. The first five rows describe the matrix of loading. 

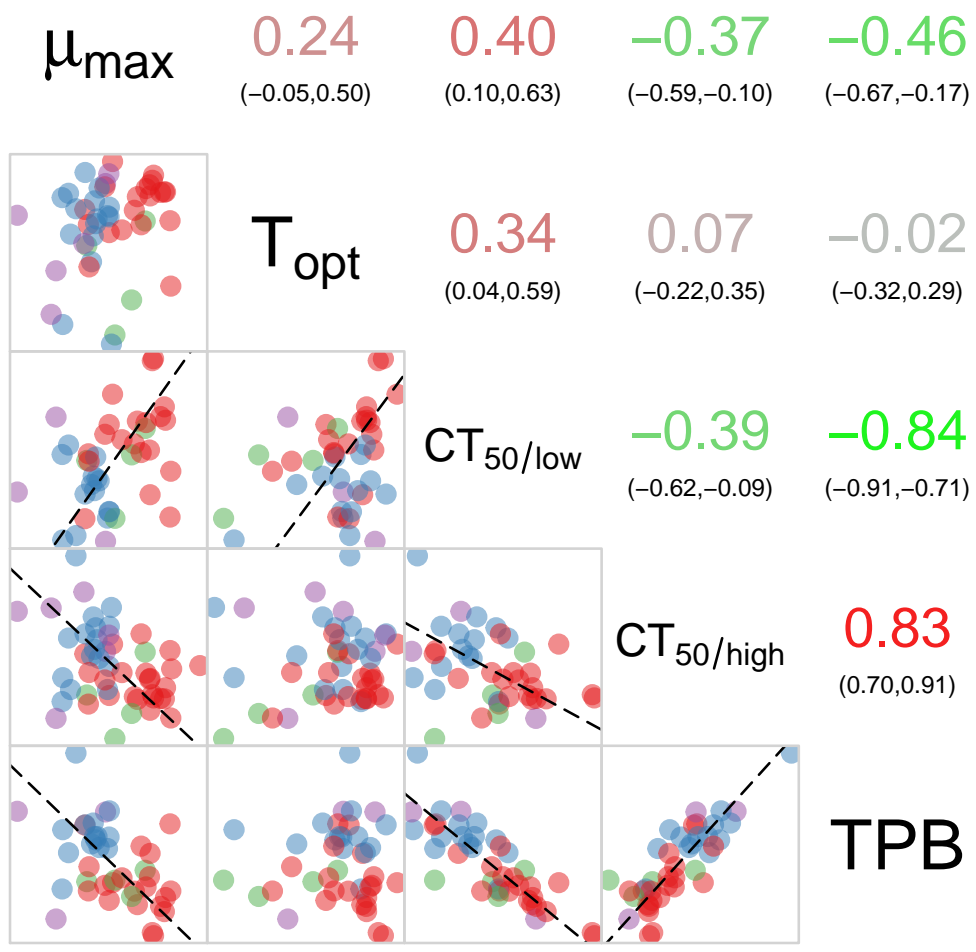


\section{PC1: $46 \%$ var}

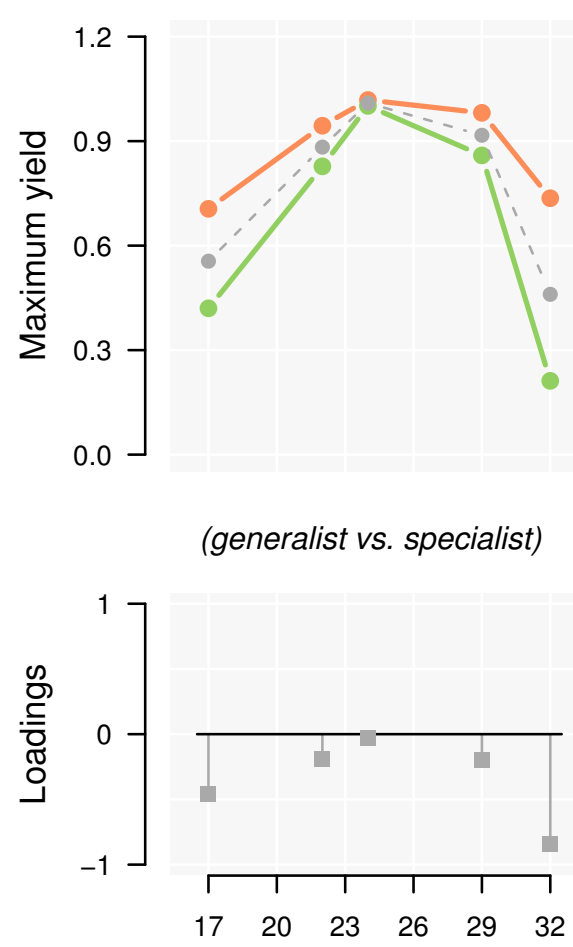

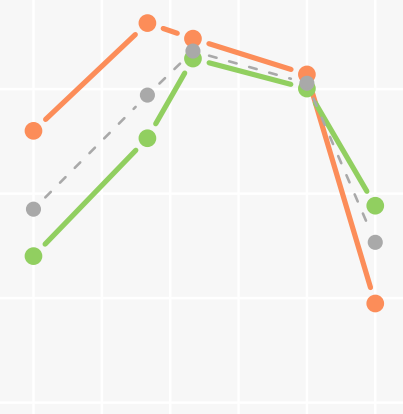

(cold-vs. warm-adapted)

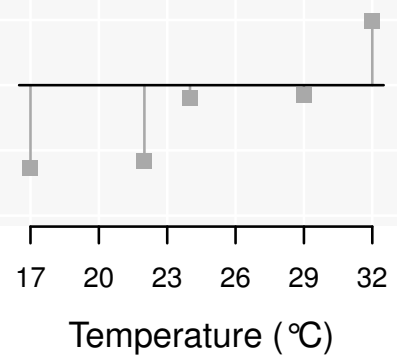

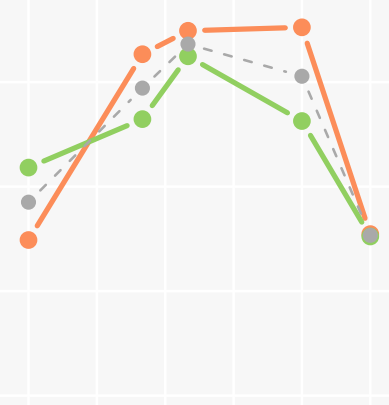

(trade-off max. perf. vs. cold adaptation)

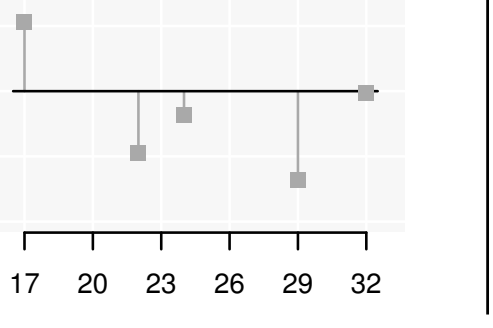

Legend for maximum yield trajectories along PCs (e.g. along PC1)

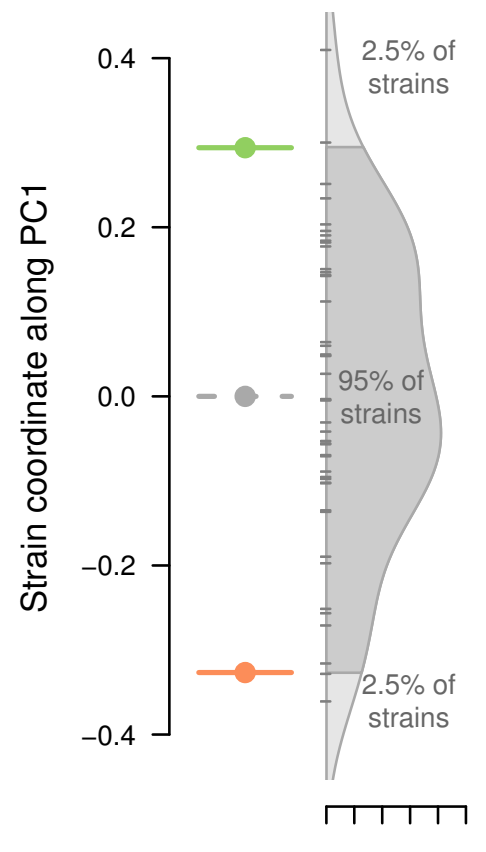



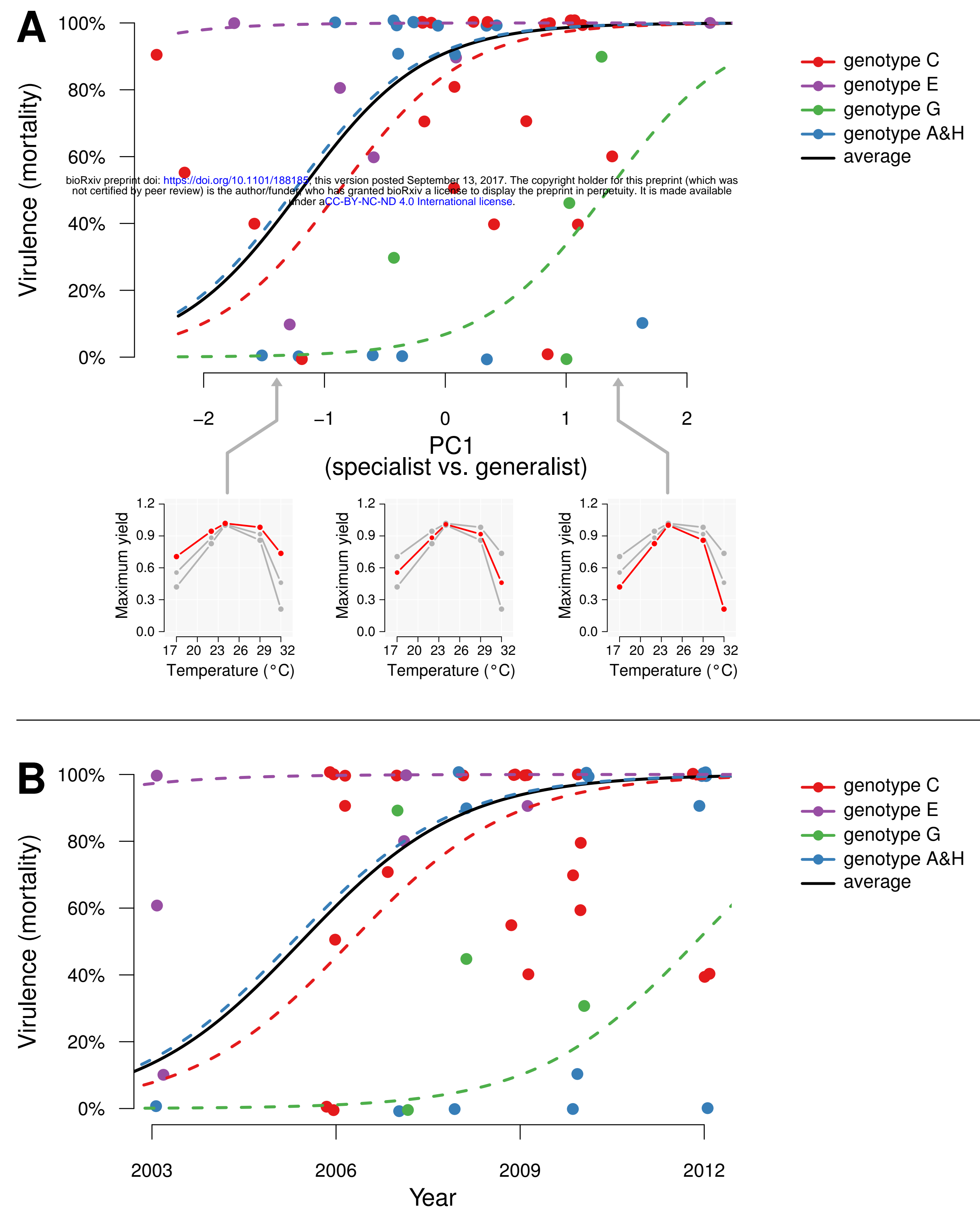